\title{
Photoredox Catalysis Using Heterogenized Iridium Complexes
}

\author{
Kelly L. Materna*, Leif Hammarström \\ Department of Chemistry-Ångström Laboratories, Uppsala University, Box 523, SE75120 \\ Uppsala, Sweden.
}

*Corresponding author: kelly.materna@kemi.uu.se

\begin{abstract}
Heterogenized photoredox catalysts provide a path to generating chemicals in an environmentally friendly way, with facile reuse of catalysts in batch or continuous processes. In this study, heterogenized iridium complexes as photoredox catalysts were assembled via covalent attachment to three metal oxide surfaces (ITO, $\mathrm{ZrO}_{2}, \mathrm{Al}_{2} \mathrm{O}_{3}$ ) either in the form of thin films or nanopowders and tested as photoredox catalysts for reductive dehalogenation of bromoacetophenone to acetophenone. All catalysts produced acetophenone with high conversions and yields. The fastest reactions were complete in fifteen minutes under mild conditions using $\mathrm{Al}_{2} \mathrm{O}_{3}$ surfaces, which provided the most robust and reusable supports. The catalytic performance was compared on both nanopowder and thin film supports, showing that both constructs could be used for photoredox catalysis. The nanopowder-based catalysts resulted in faster and more efficient catalysis, while the thin film-immobilized catalysts were more robust and easily reused. Importantly, the thin film constructs show promise for future photoelectrochemical and electrochemical photoredox setups. Finally, all catalysts could be reused 2-3 times, performing at least 1000 turnovers with $\mathrm{Al}_{2} \mathrm{O}_{3}$ supports, highlighting that heterogenized catalysts can perform photoredox catalysis in an environmentally friendly fashion.
\end{abstract}

Keywords: photoredox catalysis, iridium, heterogenized, metal oxide, solar chemicals 


\section{Introduction:}

Due to the active occurrence of climate change and its impending consequences, the world today requires renewable energy sources to drive components of daily life. ${ }^{1,2}$ Much progress has been made in the solar fuels and photovoltaics communities, where sunlight is used to generate electricity using solar cells, and produce renewable fuels, such as $\mathrm{H}_{2}$, using photoelectrochemical cells. ${ }^{3-10}$ For example, water-splitting dye sensitized photoelectrochemical cells (WS-DSPEC) incorporate molecular photosensitizers to harvest sunlight and perform charge separation and use molecular catalysts to drive fuel production; these molecular components are covalently attached to semiconducting metal oxide surfaces. The molecular nature of the components in WS-DSPECs makes them highly tunable, while the metal oxide surface provides a robust platform for photoelectrocatalysis. However, because the devices are complex, with multiple molecular components and a semiconducting surface that participates during catalysis, fuel production can be challenging as multiple charges must be accumulated for the catalyst to turnover. ${ }^{11-18}$

Complementary to this, the photoredox catalysis field has demonstrated that a variety of chemicals (natural products, pharmaceuticals, feedstock chemicals, etc.) can be produced in an environmentally friendly fashion under mild conditions using common household light bulbs. ${ }^{19-24}$ Upon illumination, molecular photoredox catalysts generate longlived excited states (ns- $\mu$ s), which are able to react with organic substrates in a reaction mixture. Typically in photoredox catalysis, catalysts are homogenous, molecular species such as ruthenium, iridium, or copper coordination complexes; these inorganic coordination complexes undergo a metal to ligand charge transfer (MLCT) and intersystem crossing (ISC) upon excitation, producing long-lived excited states, which are simultaneously highly reducing and oxidizing in nature (Scheme 1). ${ }^{23-25}$ Given this duality of the excited state, the complexes can act as effective photoredox catalysts in a library of organic transformations. 


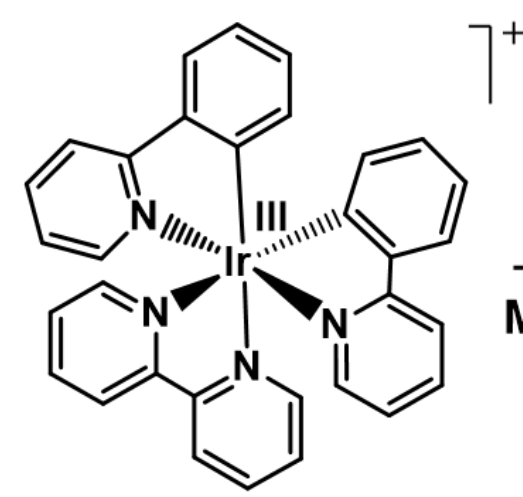

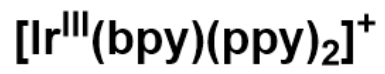

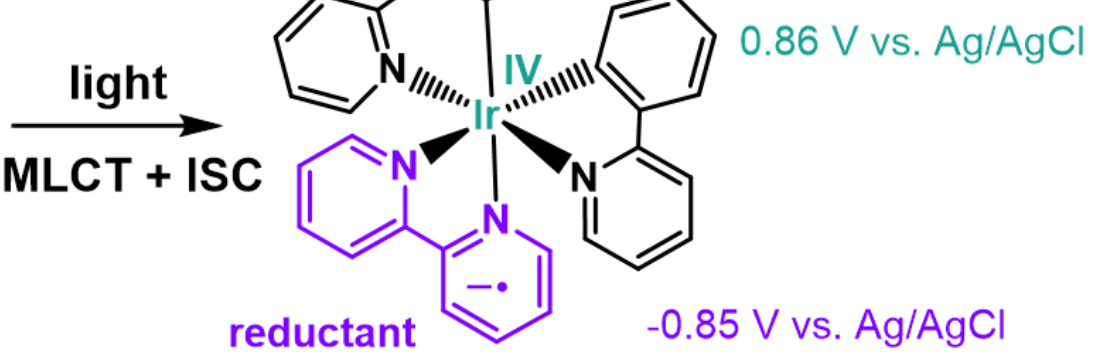

$\left[\mathrm{Ir}^{\mathrm{IV}}\left(\mathrm{bpy}^{\bullet-}\right)(\mathrm{ppy})_{2}\right]^{+}$

Scheme 1. Example reaction of photoredox catalyst $\left[\operatorname{Ir}^{\mathrm{III}}(\mathrm{bpy})(\mathrm{ppy})_{2}\right]^{+}$with light, where ppy=2phenylpyridine, and bpy=2,2'-bipyridine. ${ }^{26}$ The catalyst undergoes a metal to ligand charge transfer (MLCT) and intersystem crossing (ISC) to form the charge separated excited state species. Excited state potentials displayed in the scheme are based on literature data collected in acetonitrile under argon. ${ }^{26}$

Furthermore, homogeneous molecular photoredox catalysts have the advantage of being highly tunable due to their molecular nature, allowing a variety of organic transformations to be studied. However, as they are usually in the same phase as the organic substrate and product, a purification step is needed to separate them from the reaction mixture. To make the catalyst easier to separate from the reaction mixture, heterogeneous solid-state materials have also been used as photoredox catalysts. ${ }^{19}$ These catalysts are both robust and easily reusable catalysts; although, they are less tunable than molecular, homogeneous catalysts.

To assemble a catalyst that has the advantages of both a homogeneous and heterogeneous one, inspiration can be taken from the solar fuels field, by designing a photoredox catalyst that is molecular in nature, but covalently bound to a solid-state support, called a heterogenized catalyst (Figure 1). 7, 9, 27-29 By assembling a catalyst in this fashion, we gain the tunability of a molecular catalyst and also the reusability of heterogeneous catalyst to design the ultimate environmentally-friendly photoredox catalyst. 


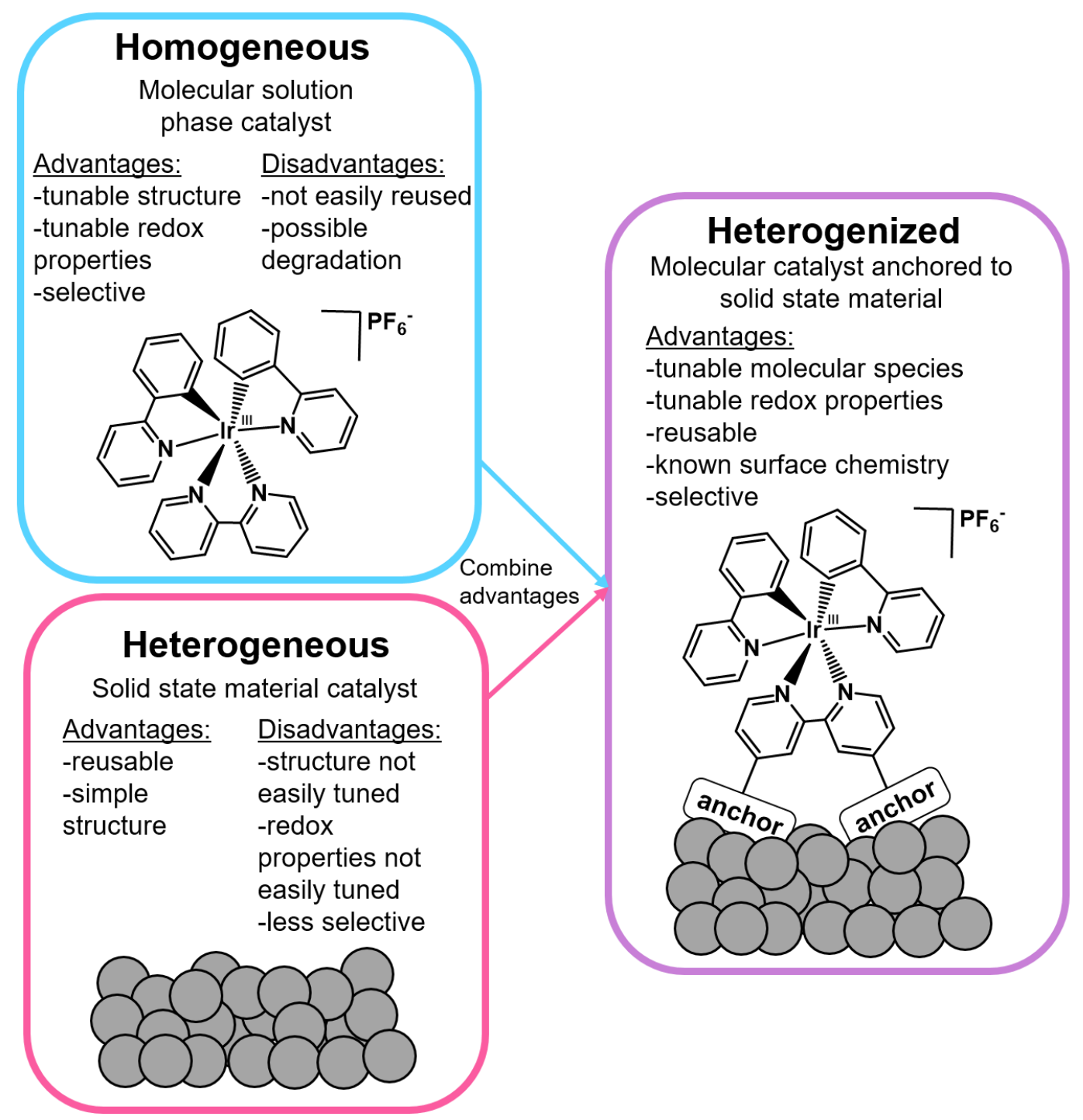

Figure 1. Differences between homogeneous, heterogeneous, and heterogenized catalysts.

In the photoredox catalysis field, this idea has not been extensively explored. A few examples exist using derivatives of tris(2,2-bipyridine)-ruthenium coordination complexes immobilized onto silica ${ }^{30,31}$, glass wool $^{32}$, or polymer ${ }^{33}$ supports. Other unique examples have also been tested such as Rose Bengal ${ }^{34}$ dye or perylene diimide (PDI) ${ }^{35}$ molecules immobilized on silica, and porphyrins immobilized onto cotton threads ${ }^{36}$. Heterogenized iridium photoredox catalysts are even less explored, with only a few examples existing where polypyridyl-based iridium complexes have been incorporated into polymer supports ${ }^{37,38}$; note that in polymer supports, iridium leaching can be an issue leading to catalyst instability. ${ }^{38}$ All of these studies demonstrate a promising future for heterogenized photoredox catalysts since they provide 
tunable and reusable catalysts; however, there lacks an organized set of guidelines for how to design a heterogenized photoredox catalyst.

To address this issue, we have chosen to study the effect of the catalyst support, by performing a systematic study using a polypyridyl iridium coordination complex immobilized onto three different metal oxide supports in the form of nanopowders or thin films. The overall goal is to develop a heterogenized catalyst that is highly functional, easily reusable, and useful in a variety of photoredox applications. In this study, photoredox catalysis for the reductive dehalogenation of 2-bromoacetophenone (BrAPN) to acetophenone (APN) was chosen as the model reaction to analyze the effect of the photoredox catalyst's support, in both content (composition of the metal oxide) and in architecture (thin film or nanopowder). This reaction is advantageous as it is simple, well-known, and is easy to follow using ${ }^{1} \mathrm{H}$ NMR spectroscopy, making it an ideal reaction for initial catalytic studies. ${ }^{39-42}$ Furthermore, the product APN is non-toxic and highly applicable in the perfume industry. Ultimately, we hope to generate an initial understanding of what materials and assembly methods provide the most functional and robust heterogenized photoredox catalysts.

\section{Results and Discussion}

Catalyst design and rationale. To design the iridium catalyst, we were inspired by the varieties of tris(2-phenylpyridine)iridium and bis(2-phenylpyridine)(2,2'bipyridine)iridium coordination complexes that are widely used in homogeneous photoredox catalysis. ${ }^{21-24,26,43,44}$ To be able to bind the complex to a metal oxide surface, carboxylic acid surface anchors were incorporated in the catalyst structure (Ir, Figure 2) by replacing a 2,2'bipyridine ligand of the latter complex for a 2,2'-bipyridine-4,4'-dicarboxylic acid ligand. Carboxylic acids are commonly used surface anchors in the solar fuels community, as they can form covalent surface bonds to a metal oxide surface. ${ }^{45}$ In addition, the photophysical properties of $\mathbf{I r}$ has been previously studied. ${ }^{46}$ Absorption features in the visible region and a long excited state lifetime (69.5 ns in acetonitrile) make it a good candidate for photoredox catalysis. 


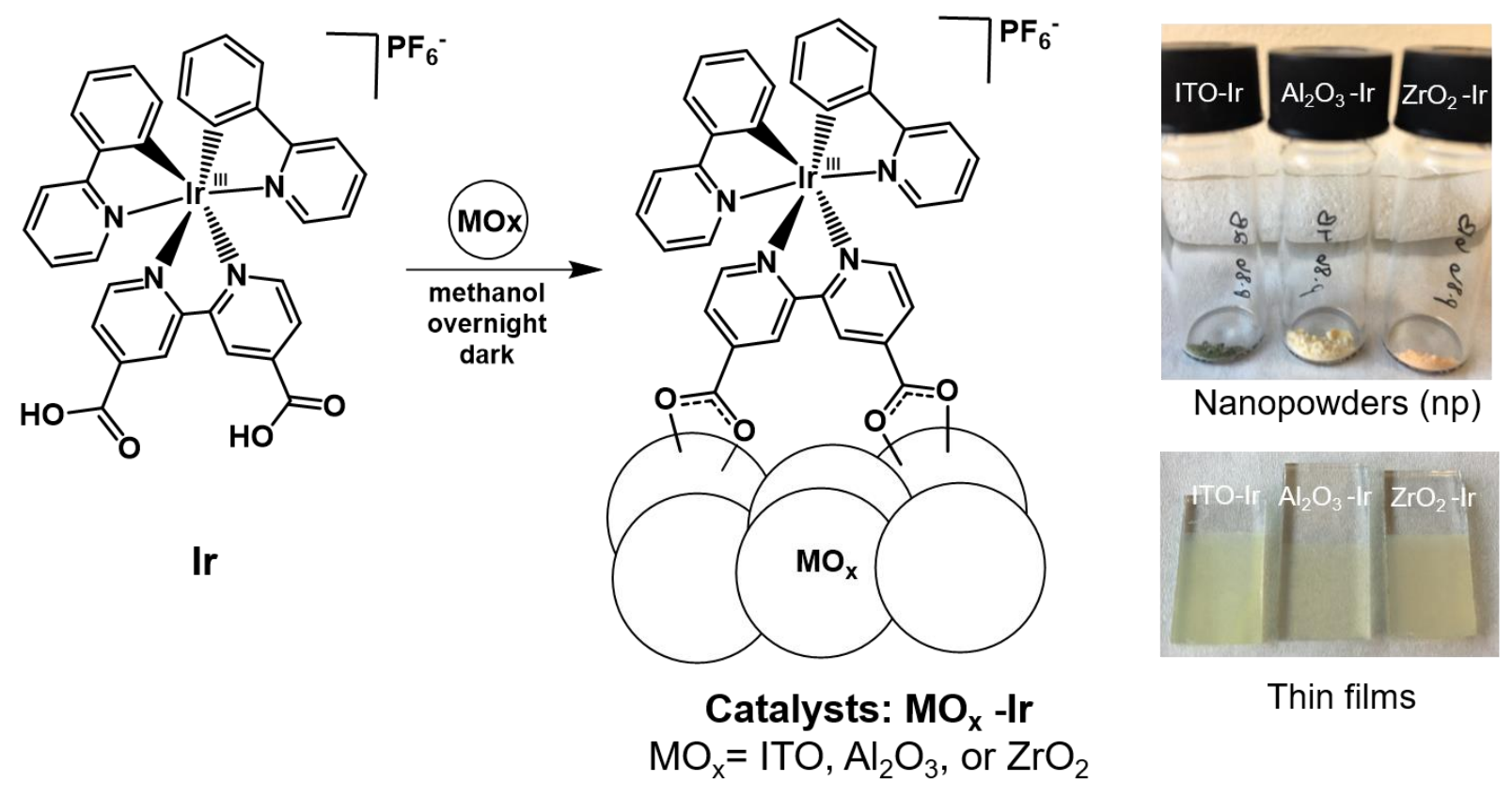

Figure 2. Structure of Ir (left complex) and proposed structure of heterogenized $\mathbf{I r}\left(\mathrm{MO}_{\mathrm{x}}-\mathbf{I r}\right)$. Preparation method for catalysts is depicted. The metal oxide nanopowders or thin films are soaked in an Ir/methanol solution overnight in the dark to provide the heterogenized catalysts (MOx-Ir). Pictures of the nanopowder catalysts are shown in the top right and thin films in the bottom right.

Ir Synthesis and Characterization. To prepare the heterogenized catalysts, Ir was synthesized via a previously reported procedure. ${ }^{46}$ Briefly, Ir was synthesized via reaction of $\left[\operatorname{Ir}(\mathrm{ppy})_{2}(\mu-\mathrm{Cl})\right]_{2}$ with 2,2'-bipyridine-4,4'-dicarboxylic acid in dichloromethane followed by workup with ammonium hexafluorophosphate, $\mathrm{NH}_{4} \mathrm{PF}_{6}$ (more details in the Supporting Information, SI). Ir was characterized by proton nuclear magnetic resonance ( ${ }^{1} \mathrm{H}$ NMR), UVVis, photoluminescence, and attenuated total reflectance Fourier transform infrared (ATRFTIR) spectroscopic measurements supporting that Ir was successfully synthesized (see SI). The UV-Vis spectrum of Ir shows a MLCT band at $370 \mathrm{~nm}$ and a broad band at $497 \mathrm{~nm}$ (Figure S10). ATR-FTIR confirms the presence of the carboxylic acid anchoring group, having a signature peak at $1709 \mathrm{~cm}^{-1}$, suggesting the presence of a $\mathrm{C}=\mathrm{O}$ group (Figure S19). The photoluminescence spectrum after excitation at $370 \mathrm{~nm}$ shows a band with maximum at 635 $\mathrm{nm}$, typical for this class of complexes (Figure S36). ${ }^{46,47}$

Metal Oxide Rationale. Three different metal oxide (MOx) supports were chosen to be examined: $\mathrm{Al}_{2} \mathrm{O}_{3}, \mathrm{ZrO}_{2}$, and ITO. $\mathrm{Al}_{2} \mathrm{O}_{3}$ and $\mathrm{ZrO}_{2}$ are wide band gap semiconductors, while ITO is a conductive metal oxide. Since $\mathrm{Al}_{2} \mathrm{O}_{3}(8.45-9.9 \mathrm{eV})$ and $\mathrm{ZrO}_{2}(5$ 
$\mathrm{eV}$ ) have wide band gaps and high energy conduction bands, ${ }^{48}$ and Ir's redox potentials lie far from the valence and conduction band potentials, Ir should not be able to inject charges into the metal oxide upon excitation. As a result, no redox events should occur between the catalyst and metal oxide. Therefore, the metal oxide should only act as a support for the molecular catalyst and should not actively participate in catalysis (unlike semiconductors with lower energy conduction bands, such as $\mathrm{TiO}_{2}$ and $\mathrm{ZnO}$ where charge injection could occur). This allows us to probe Ir's activity in photoredox catalysis with less interference from the surface. To increase catalyst applicability in future heterogenized setups, ITO (indium doped tin oxide) was also chosen as it is a conducting metal oxide, having a continuous electronic band structure(i.e. no band gap); ITO itself should not undergo light induced reactions, and thus, should mainly act as a catalyst support (although electron injection from the catalyst might occur ${ }^{10,49}$ ). Further, ITO is advantageous as it can be applied as an electrode material in (photo)electrochemical setups in future studies, ${ }^{28}$ which would allow sacrificial reagents to be eliminated from reactions as charges could be provided by the counter electrode in an external circuit; this would create a more environmentally-friendly way to do photoredox catalysis.

Metal Oxide Architectures. The effect of the metal oxide architecture was also examined, either as nanopowders or thin films. Some differences in reactivity, reusability, and applicability may be found with the different architectures (Table 1). For example, nanopowders can be stirred in a reaction, minimizing concentration gradients by enabling fast catalyst transport to the BrAPN substrate, which should result in quick reactions. In contrast, thin films reactions have no catalyst diffusion or transport via stirring as the catalyst is immobilized onto a metal oxide thin film annealed to a glass slide. The substrate must be transported to the catalyst within the film via stirring and diffusion; thus, slower reactions with thin films are expected. The quantity (equivalents) of $\mathbf{I r}$ in the reactions with nanopowder supports can be more easily modified than thin films, as more nanopowder $\mathrm{MO}_{\mathrm{x}}-\mathbf{I r}$ can simply be added to the reaction. Whereas, to increase the quantity (equivalents) of catalyst with the thin films (if the catalyst loading is already maximized), a larger geometric surface area and/or thicker films would be needed to add more MOx-Ir. Since the films are placed in the reaction vessel, the vessel must be large enough to fit a larger film, which could require a custom designed vessel. Regarding reusability, thin films are advantageous since they can be easily removed from the reaction without losing any catalyst. In contrast, nanopowder-based catalysts require centrifugation or filtration to remove the catalyst and several rinsing steps, which could result in some catalyst loss over time, thus limiting the long-term reusability. Thin films can be 
easier to characterize by spectroscopic methods (UV-Vis, ATR-FTIR, TCSPC, XPS) as they are transparent in nature, possibly having a more evenly distributed catalyst loading, and can be studied as prepared unlike nanopowders. Finally, thin films have the more applicable architecture when it comes to future electrochemical or photoelectrochemical setups as an FTOcoated glass electrode is used to support the thin film in these devices and provide a conductive contact in the electrical circuit.

Table 1. Advantages and disadvantages of thin films versus nanopowders.

\begin{tabular}{|c|c|c|c|}
\hline \multicolumn{2}{|c|}{ Thin Films } & \multicolumn{2}{|c|}{ Nanopowders } \\
\hline 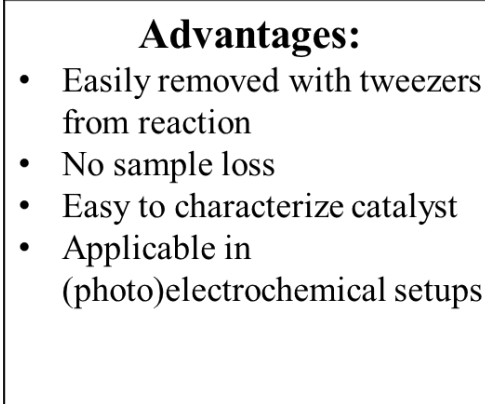 & 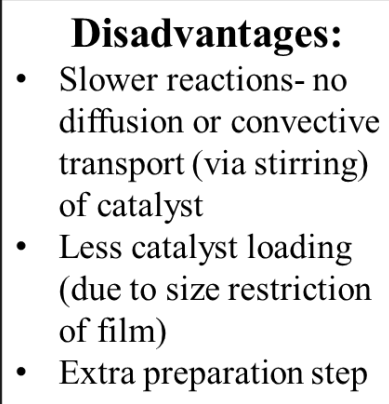 & 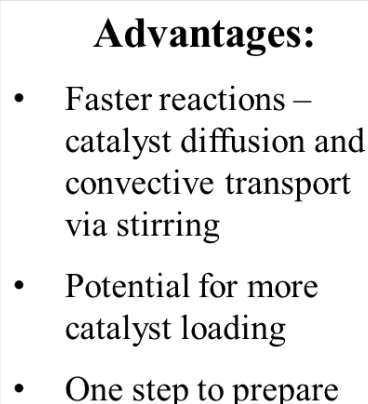 & $\begin{array}{l}\text { Disadvantages: } \\
\text { - Sample loss due to } \\
\text { centrifugation and } \\
\text { rinsing } \\
\text { - Harder to } \\
\text { characterize catalyst }\end{array}$ \\
\hline
\end{tabular}

Preparation of Heterogenized Nanopowder Catalysts. To prepare the heterogenized catalysts, approximately $25 \mathrm{mg}$ of nanopowder $\left(\mathrm{Al}_{2} \mathrm{O}_{3}, \mathrm{ZrO}_{2}\right.$, ITO) was stirred in the presence of $2.5 \mathrm{~mL}$ of a $0.25 \mathrm{mM}$ solution of $\mathbf{I r}$ in methanol overnight in the dark. Post sensitization, the catalyst was centrifuged off from the sensitization solution and rinsed three times with methanol via subsequent rinsing and centrifugation steps. Finally, the catalyst was dried under vacuum for several hours, affording the MOx-Ir nanopowders (Figure 2).

Preparation of Heterogenized Thin Film Catalysts. To prepare the thin film based catalysts, metal oxide thin films were first prepared. One layer of metal oxide paste was doctor bladed onto FTO-coated glass slides, followed by annealing at high temperatures for several hours (see SI for further details). The thin films were then soaked in a $0.1 \mathrm{mM} \mathrm{Ir}$ sensitization solution in methanol overnight, rinsed with methanol three times, and air-dried (Figure 2).

Catalyst Characterization. Several spectroscopic methods were used to characterize the catalysts. First, UV-Vis spectroscopy was used to analyze the Ir surface loadings on the nanopowders and thin films. For the nanopowders, the depletion method was used to quantify the Ir surface loadings. ${ }^{28,50}$ To do this, the UV-Vis spectrum of the sensitization solution was collected before and after exposure to the nanopowders to get the 
initial and final iridium concentrations in the solutions using the molar extinction coefficient, $\varepsilon(370 \mathrm{~nm})=8730 \mathrm{~cm}^{-1} \mathrm{M}^{-1}$ (Figure S10). After sensitization of the nanopowders and centrifugation, a decrease in absorbance at $370 \mathrm{~nm}$ was observed in the supernatant, suggesting that the iridium complex in solution had bound to the nanopowders (Figure S12). The difference in iridium concentration before and after sensitization was calculated and approximated to be the loading on the surface. For the samples, an average loading of $6.0 \pm 0.9 \mathrm{nmol} / \mathrm{mg}$ for $\mathrm{Al}_{2} \mathrm{O}_{3}-$ Ir, $7.1 \pm 0.8 \mathrm{nmol} / \mathrm{mg}$ for $\mathrm{ZrO}_{2}$-Ir, and $6.7 \pm 0.9 \mathrm{nmol} / \mathrm{mg}$ for ITO-Ir was obtained (Table S1). For the thin films, UV-Vis spectra was collected directly on the thin films, showing similar absorption features to the $\mathbf{I r}$ in solution, suggesting the molecular structure had been retained upon surface binding (Figure 3$)$. The loadings $(\Gamma)$ were obtained using the formula, $\Gamma\left(\mathrm{mol} \mathrm{cm}^{-2}\right.$ )$=\mathrm{A}(\lambda) /(1000 \varepsilon)$, where $\mathrm{A}$ is the absorbance at wavelength $\lambda$, and $\varepsilon$ is the molar extinction coefficient at wavelength $\lambda .{ }^{51}$ Average loadings were calculated and found to be $28.4 \pm 6.9$ $\mathrm{nmol} / \mathrm{cm}^{2}$ for $\mathrm{Al}_{2} \mathrm{O}_{3}-\mathbf{I r}, 31.1 \pm 8.7 \mathrm{nmol} / \mathrm{cm}^{2}$ for $\mathrm{ZrO}_{2}-\mathbf{I r}$, and $35.8 \pm 7.0 \mathrm{nmol} / \mathrm{cm}^{2}$ for ITO-Ir (Table S2).

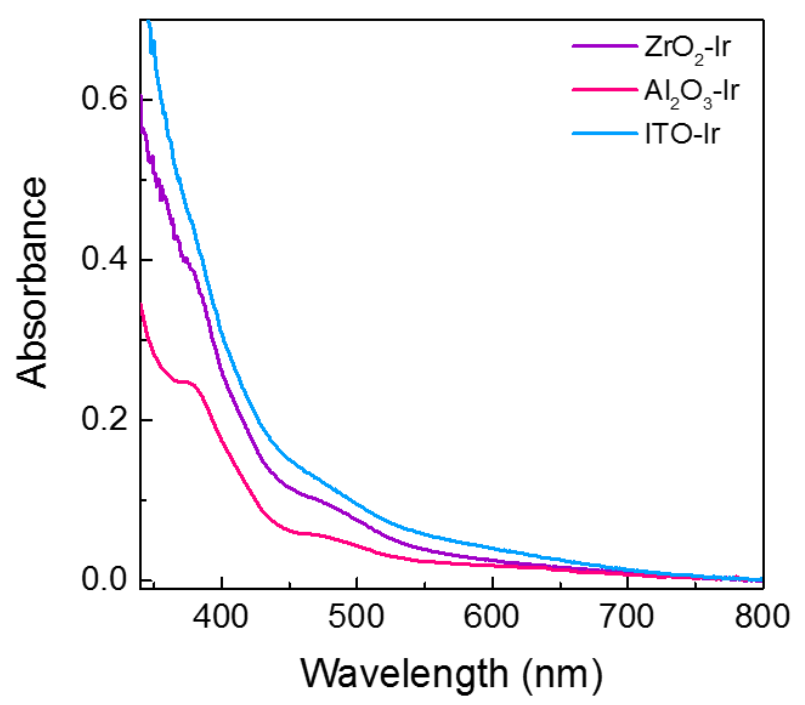

Figure 3. UV-Vis spectra of thin films of $\mathrm{ZrO}_{2}-\mathbf{I r}$ (purple), $\mathrm{Al}_{2} \mathrm{O}_{3}-\mathbf{I r}$ (pink), ITO-Ir (blue).

To further characterize the heterogenized catalysts, ATR-FTIR, and XPS were collected on the nanopowders and thin films. In the ATR-FTIR spectra, $\mathrm{C}=\mathrm{C}$ and $\mathrm{C}=\mathrm{N}$ aromatic stretches at $1607 \mathrm{~cm}^{-1}$ and $1583 \mathrm{~cm}^{-1}$, respectively, are observed in both $\mathbf{I r}$ powder and $\mathrm{MO}_{\mathrm{x}}-\mathbf{I r}$ samples, suggesting that the molecular structure is retained upon binding (Figure S20-21). Xray photoelectron spectroscopic (XPS) measurements also show characteristic peaks for Ir in the iridium $4 \mathrm{f}$ region at $61.8 \mathrm{eV}$ and $64.7 \mathrm{eV}$, which match well with the Ir powder XPS 
spectrum, supporting the presence of iridium on the metal oxides (Figure S26-27). Based on the UV-Vis, ATR-FTIR, and XPS spectroscopic data, Ir has successfully bound to the metal oxides and is likely a molecular complex on the surface.

Electrochemistry. To ensure that Ir is capable of reducing the BrAPN substrate, cyclic voltammetric $(\mathrm{CV})$ measurements were performed on ITO-Ir to get the reduction potentials of the heterogenized catalyst. The CVs in acetonitrile showed quasi-reversible reduction and oxidation waves, at $-1.93 \mathrm{~V}$ vs. $\mathrm{Fc} / \mathrm{Fc}^{+}$and $0.98 \mathrm{~V}$ vs. $\mathrm{Fc} / \mathrm{Fc}^{+}$, respectively (Figure $\mathrm{S} 32$ ), while the $\mathrm{CV}$ of BrAPN showed an irreversible reduction at $-1.73 \mathrm{~V}$ vs. $\mathrm{Fc} / \mathrm{Fc}^{+}$(Figure S33). These potentials confirm that the reduced $\mathbf{~ I r}^{-}$should be thermodynamically able to reduce BrAPN.

Excited State Potentials. Excited state potentials for Ir were estimated from the UV-Vis absorption spectrum, photoluminescence spectrum, and ground state redox potentials using Weller approximations. ${ }^{52}$ Intersection of the normalized absorption and emission spectra give an estimated transition energy from the ground state to the lowest excited state (E0-0) of $2.21 \mathrm{eV}$ (Figure S36). Using the Weller approximations, excited state potentials were estimated to be $-1.23 \mathrm{~V}$ vs. $\mathrm{Fc} / \mathrm{Fc}^{+}$for $\operatorname{Ir}^{+} / \mathrm{Ir}^{*}\left(\mathrm{E}^{0}\left(\operatorname{Ir}^{+} / \mathrm{Ir}^{*}\right)=\mathrm{E}^{0}\left(\mathrm{Ir}^{+} / \mathrm{Ir}\right)-\mathrm{E}_{0-0}\right)$ and $0.28 \mathrm{~V}$ vs. $\mathrm{Fc} / \mathrm{Fc}^{+}$for $\operatorname{Ir}^{*} / \operatorname{Ir}^{-}\left(\mathrm{E}^{0}\left(\operatorname{Ir}^{*} / \mathrm{Ir}^{-}\right)=\mathrm{E}^{0}\left(\operatorname{Ir} / \mathrm{Ir}^{-}\right)+\mathrm{E}_{0-0}\right)$. Thus, the $\mathbf{I r}$ excited state is thermodynamically unable to reduce the substrate during photoredox catalysis. Furthermore, one should note that triethanolamine (TEOA) is also present during the reductive dehalogenation reactions as a sacrificial electron donor and proton source. The TEOA reduction potential is estimated to be $0.3 \mathrm{~V}$ vs. $\mathrm{Fc} / \mathrm{Fc}^{+}[0.7 \mathrm{~V}$ vs. SCE, ref. 53] but as its' oxidation is irreversible, this value should be taken as an approximation and not a fixed value; hence, the Ir excited state is most likely quenched by TEOA during photoredox catalysis.

Time Correlated Single Photon Counting. Prior to catalytic testing, the catalyst excited state lifetimes were quantified using time correlated single photon counting (TCSPC) measurements to ensure they did not change significantly upon surface binding and had long enough lifetimes for photoredox reactions ( $>1 \mathrm{~ns}$ needed). For the measurements, Ir was excited with a $470 \mathrm{~nm}$ laser pulse, and the photoluminescence from the excited state was monitored over time via collection of single photon events (Figure S34). ${ }^{54,55}$ Decays were fit to mono or biexponential functions and the results can be found in Table S5. Using monoexponential fits, $\tau_{1}=220 \mathrm{~ns}$ was found for $\mathrm{ZrO}_{2}$-Ir. This lifetime is similar to that of the homogeneous version of Ir, having $\tau_{1}=210 \mathrm{~ns}$. Biexponential fits were used for $\mathrm{Al}_{2} \mathrm{O}_{3}$ - $\mathbf{I r}$ and ITO-Ir as these did not 
fit well to single exponential decays; this could be due to surface inhomogeneity or noninnocent surface behavior. For these surfaces, an average excited state lifetime ( $\left.\tau_{\text {average }}\right)$ of 1.5 ns was found for ITO-Ir, and 3.3 ns for $\mathrm{Al}_{2} \mathrm{O}_{3}-\mathbf{I r}$. The overall trend in catalyst excited state lifetime was then $\mathrm{ZrO}_{2}-\mathbf{I r}>\mathrm{Al}_{2} \mathrm{O}_{3}$ - $\mathbf{I r}>$ ITO-Ir. It is possible that the conductivity of ITO interferes some with the Ir excited state (via electron injection into ITO), causing a faster excited state decay, ${ }^{10,}{ }^{49}$ while potential surface trap states in $\mathrm{Al}_{2} \mathrm{O}_{3}$, may also shorten the lifetimes. ${ }^{56,57}$ Nevertheless, all samples show excited state lifetimes longer than $1 \mathrm{~ns}$, which the minimum lifetime needed to react with a substrate diffusing in a reaction mixture. Thus, all catalysts are good candidates for photoredox tests.

Catalyst Stability. As catalyst desorption can occur in heterogenized systems, ${ }^{45}$ a quick check was performed prior to catalytic tests to ensure that Ir was stable on the surface in the reaction solvent, acetonitrile. No catalyst loss from the metal oxide was observed after soaking MOx-Ir in acetonitrile overnight (Figure S17). In addition, no light induced desorption was observed when the metal oxide was illuminated with a white light lamp in acetonitrile (Figure S17).

Initial Catalytic Tests. Since Ir had been successfully characterized on the three surfaces, and had properties promising for photoredox catalysis, initial reductive dehalogenation tests were conducted. A reaction scheme is depicted in Scheme 2 for the reductive dehalogenation of BrAPN to APN. We were inspired by results from a Tris(bipyridine) $\mathrm{Ru}(\mathrm{II})$ metal organic framework (MOF) photoredox catalyst reported to catalyze reductive dehalogenation reactions. ${ }^{39}$ In the reaction mixture, triethanolamine (TEOA) was also present to act as a sacrificial electron donor and proton source. During each reaction, BrAPN, TEOA, and $\mathrm{MO}_{\mathrm{x}}-\mathbf{I r}(0.2 \mathrm{~mol} \%)$ were added to a vial with deuterated acetonitrile $\left(\mathrm{CD}_{3} \mathrm{CN}\right)$ and a stir bar. The reaction was sealed and degassed with Ar prior to measurement and kept as dark as possible (more reaction details in SI). Reactions were stirred rapidly at 1000 RPM, and illuminated with a blue Kessil LED with a 435 long pass filter, placed precisely 3 $\mathrm{cm}$ away from the vial $\left(\sim 125 \mathrm{~mW} / \mathrm{cm}^{2}\right)$; the reaction was also kept cool with a fan blowing on it at all times. These conditions were kept constant to minimize error between measurements (extra details in SI). 


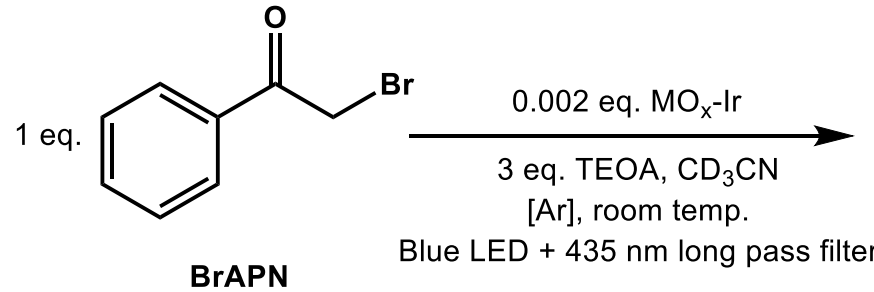<smiles>CC(=O)c1ccccc1</smiles>

Scheme 2. Reaction conditions for reductive dehalogenation of bromoacetophenone (BrAPN) to acetophenone (APN).

The photoredox catalytic reactions were initially examined using the nanopowder catalysts over two hours of reaction time (Table 2, entry 1-3). Reactions were performed in $\mathrm{CD}_{3} \mathrm{CN}$ in order to analyze the reaction mixture by ${ }^{1} \mathrm{H}$ NMR spectroscopy (details in $\mathrm{SI}$ ). Importantly, a main advantage of this reaction is that it is easily followed by ${ }^{1} \mathrm{H}$ NMR as BrAPN and APN have singlets in non-overlapping regions; BrAPN has a singlet at $4.68 \mathrm{ppm}$ for its $\mathrm{CH}_{2}$ while APN has a singlet at $2.56 \mathrm{ppm}$ for its $\mathrm{CH}_{3}$ (Figure S7). Amazingly, all nanopowder catalysts showed full conversion to APN after two hours of reaction.

Table 2. Reaction yields for reductive dehalogenation of bromoacetophenone to acetophenone with $\mathrm{MO}_{\mathrm{x}}$-Ir nanopowders and control reactions after two hours.

\begin{tabular}{|c|c|c|c|}
\hline Entry & Sample & Light / Dark & \% Yield APN \\
\hline 1 & $\mathrm{ITO}-\mathrm{Ir}$ & Light & 100 \\
\hline 2 & $\mathrm{Al}_{2} \mathrm{O}_{3}-\mathrm{Ir}$ & Light & 100 \\
\hline 3 & $\mathrm{ZrO}_{2}-\mathrm{Ir}$ & Light & 100 \\
\hline 4 & $\mathrm{ITO}$ & Light & 0 \\
\hline 5 & $\mathrm{Al}_{2} \mathrm{O}_{3}$ & Light & 2 \\
\hline 6 & $\mathrm{ZrO}_{2}$ & Dark & 0 \\
\hline 7 & $\mathrm{ITO}_{-} \mathrm{Ir}$ & Dark & 0 \\
\hline 8 & $\mathrm{Al}_{2} \mathrm{O}_{3}-\mathrm{Ir}$ & Dark & 0 \\
\hline 9 & $\mathrm{ZrO}_{2}-\mathrm{Ir}$ & Light & 23 \\
\hline $10^{\mathrm{a}}$ & $\mathrm{ITO}_{-} \mathrm{Ir}$ & Light & 25 \\
\hline $11^{\mathrm{a}}$ & $\mathrm{Al}_{2} \mathrm{O}_{3}-\mathrm{Ir}$ & Light & 20 \\
\hline $12^{\mathrm{a}}$ & $\mathrm{ZrO}_{2}-\mathrm{Ir}$ & Light & 0 \\
\hline $13^{\mathrm{b}}$ & $\mathrm{ITO}-\mathrm{Ir}$ & Light & 0 \\
\hline $14^{\mathrm{b}}$ & $\mathrm{Al}_{2} \mathrm{O}_{3}-\mathrm{Ir}$ & Light & 0 \\
\hline $15^{\mathrm{b}}$ & $\mathrm{ZrO}_{2}-\mathrm{Ir}$ & & \\
\hline
\end{tabular}




\begin{tabular}{|c|c|c|c|}
\hline 16 & No catalyst & Light & 0 \\
\hline $17^{\mathrm{c}}$ & No catalyst & Light & 16 \\
\hline
\end{tabular}

${ }^{\mathrm{a}}$ reactions used a ratio of BrAPN:TEOA:MO $\mathrm{MO}_{\mathrm{x}}$-Ir of 1:0.5:0.002; ${ }^{\mathrm{b}} 0$ equivalents of triethanolamine in reaction; ${ }^{\mathrm{c}}$ reaction performed without $435 \mathrm{~nm}$ long pass filter.

Reaction Controls. Since the reactions showed all catalysts were functional, several controls were then performed to make sure catalysis was occurring as expected (Table 2). First, we tested to ensure the catalyst was necessary for the reaction to occur (entry 16). No APN was formed when the catalysts were removed from the reaction mixture, suggesting they were necessary for catalysis. To ensure that the molecular catalyst was necessary, controls were performed with just the metal oxide nanopowders (without catalyst bound) in the reaction (entry 4-6). Insignificant APN was produced, suggesting that the molecular component is necessary for photoredox catalysis. Furthermore, the reactions do not work in the dark, suggesting that light is necessary to excite the catalyst and promote turn over (entry 7-9). In addition, the necessity for triethanolamine was tested. No APN was formed without TEOA present (entry 13-15), as this is likely needed to i.) reduce the iridium excited state, Ir*, and ii.) donate a proton to the reduced BrAPN species, which forms the APN product. When the concentration of TEOA is half that of BrAPN (entry 10-12), reaction yields are only 20-25\%, suggesting there is not enough reagent around to finish the catalytic reaction. Finally, when the concentration of TEOA is three times that of BrAPN (entry 1-3), reactions yields go to completion. This trend suggests that we do need TEOA in the reaction mixture and in excess to the BrAPN substrate.

Finally, as there is always a possibility that catalyst desorption can occur in heterogenized systems, ${ }^{45}$ we wanted to check that the active catalyst was indeed heterogenized and not a desorbed homogeneous catalyst. To do this, the reaction yield was analyzed after a few minutes (to ensure the reaction was not complete), catalyst removed from the mixture, and APN yield quantified. The reaction was then continued without the catalyst present to see if the yields changed when the catalyst was removed. If the yield increased, this would suggest that the active catalyst was actually a desorbed Ir species and not the heterogenized catalyst. If the yield did not change, then the active catalyst is likely heterogenized. Indeed, for all catalysts the yield did not increase significantly, suggesting that the active catalyst was heterogenized (Figure 4). Moreover, if the catalyst was added back into the reaction, yields increased again, further confirming that the catalyst was heterogenized (Figure 4). 

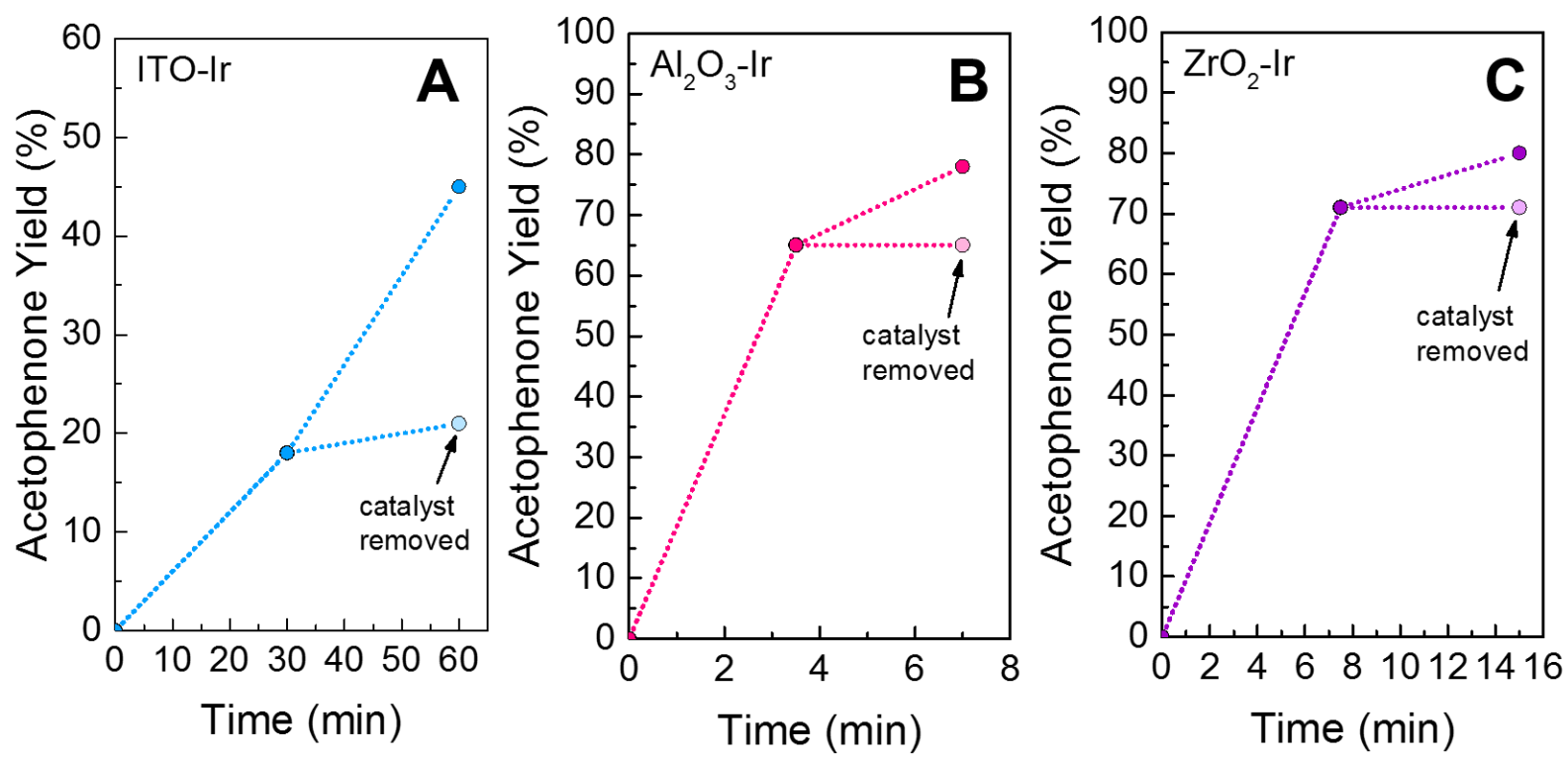

Figure 4. Heterogenized tests for (A) ITO-Ir (blue) (B) $\mathrm{Al}_{2} \mathrm{O}_{3}$ - $\mathrm{Ir}$ (pink), (C) $\mathrm{ZrO}_{2}$-Ir (purple). Reactions were run for a few minutes, catalyst removed from the reaction mixture and yields quantified. The reaction was continued without the catalyst for a few more minutes, and the yield checked again (light colored circle). This was compared to when the catalyst was added in the reaction for the same amount of time.

Mechanistic Insight. Since the controls suggested that the catalyst was functioning as a heterogenized catalyst, we postulated what mechanistically could be occurring in the reaction mixture. Based on the above controls and electrochemical data, we proposed that upon illumination i.) Ir becomes photoexcited forming the excited state species ii). the excited state species is reduced by TEOA forming the reduced iridium catalyst, and the reduced catalyst reduces the BrAPN substrate, which goes on to form the product through subsequent reduction and protonation steps (Figure 5). To further support this hypothesis, TCSPC measurements were performed on Ir in the presence of TEOA, which showed evidence for excited state quenching; this is seen in the decrease in the excited state lifetimes from $210 \mathrm{~ns}$ to $80 \mathrm{~ns}$ in the presence of TEOA (Figure S35). The excited state decay of Ir shows a much smaller change in the presence of BrAPN, with a lifetime of 180 ns (Figure S35, Table S5). These additional experiments suggest that in the catalytic cycle, excited $\mathbf{I r}$ is first reductively quenched, which is then followed by BrAPN reduction as shown in Figure 5. Recall from the electrochemical and photophysical data that the reduced state of $\mathbf{I r}$ is thermodynamically capable of reducing BrAPN, while the excited Ir* is not, further supporting the cycle in Figure 5. 


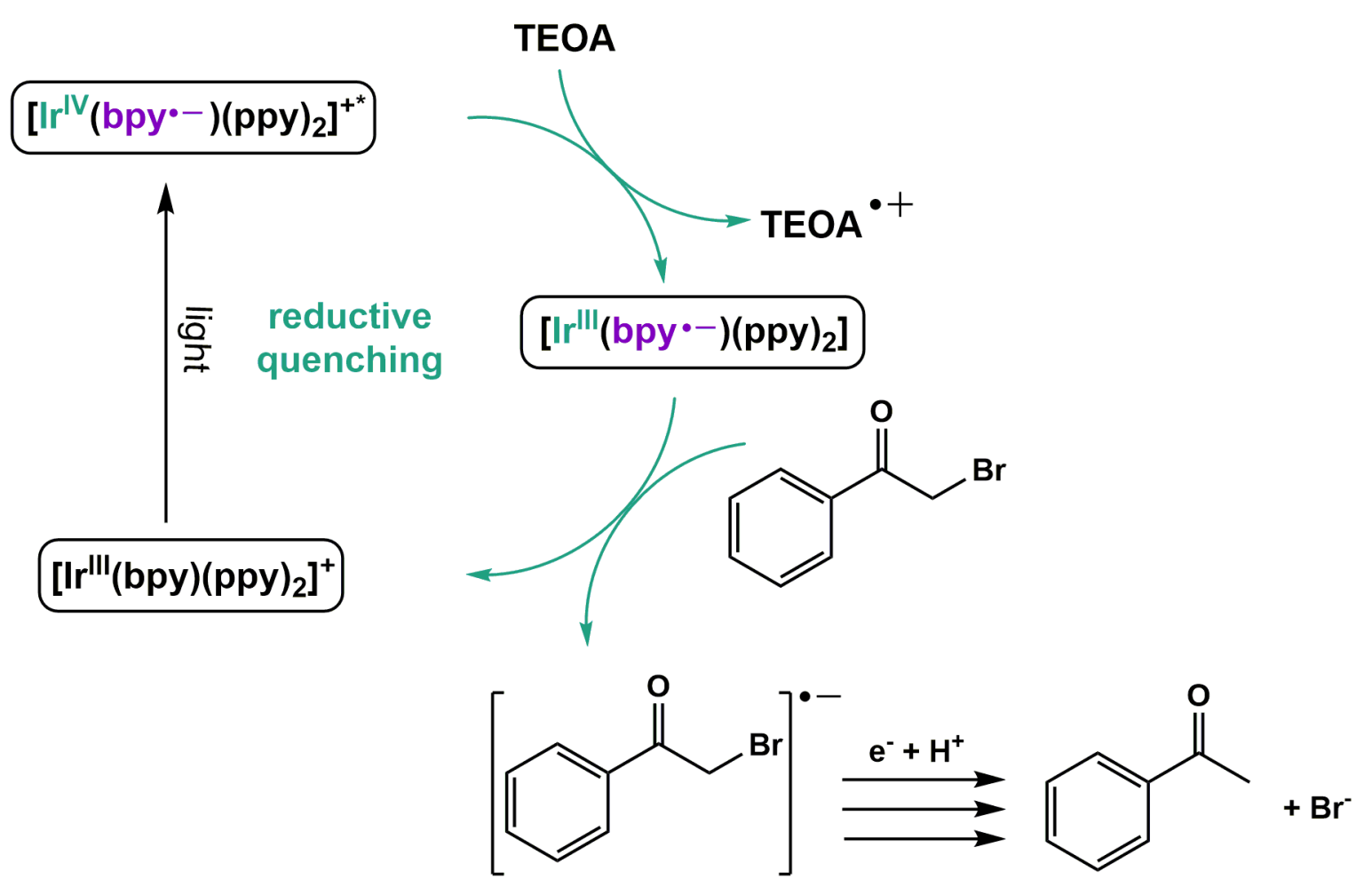

Figure 5. Proposed catalytic cycle based on TCSPC data and electrochemical data. First, Ir (depicted more precisely as $\left[\operatorname{Ir}^{\mathrm{III}}(\mathrm{bpy})(\mathrm{ppy})_{2}\right]^{+}$, where ppy=2-phenylpyridine, and bpy=2,2'bipyridine-4,4'-dicarboxylic acid) becomes photoexcited upon illumination, forming the excited iridium species ${ }^{26}$, which is then reduced by TEOA to form the reduced iridium state. Finally, the reduced iridium species reduces BrAPN, which returns Ir to its ground state. The reduced BrAPN then goes on to form the final product after subsequent reduction and protonation via reaction with the triethanolamine radical cation. ${ }^{53}$

The Need for Speed. With a grasp of what could be happening during catalysis, and as the reactions reached completion during two hours, we wondered if the reactions were complete prior to the two-hour mark. To do this, we tracked the reaction over time by ${ }^{1} \mathrm{H}$ NMR and found that indeed, the nanopowder-based catalysts were remarkably faster (Figure 6A). For example, $\mathrm{Al}_{2} \mathrm{O}_{3}$-Ir samples showed the fastest APN formation with reactions complete by 15 minutes doing 385 turnovers (limited by substrate consumption) with a turnover frequency (TOF) of $\sim 0.4 \mathrm{~s}^{-1}$. ZrO 2 -Ir samples were also fast, reaching completion after 30 minutes, being slightly slower with a TOF of $\sim 0.2 \mathrm{~s}^{-1}$. ITO-Ir was the slowest, taking the full two hours to reach completion giving it a TOF of $0.05 \mathrm{~s}^{-1}$. Clearly, the fastest catalysts are those using wide bandgap semiconductor supports, which suggests these are the optimal surfaces for the nanopowder reactions. ITO supports may have resulted in slower reactions because the Ir 
excited state lifetime is much shorter on these surfaces, or if the surface is non-innocent during catalysis (e.g. from electron injection into ITO by $\mathbf{I r}^{*}$ or $\left.\mathbf{I r}^{-}\right){ }^{10,49}$ Table 3 summarizes these findings.
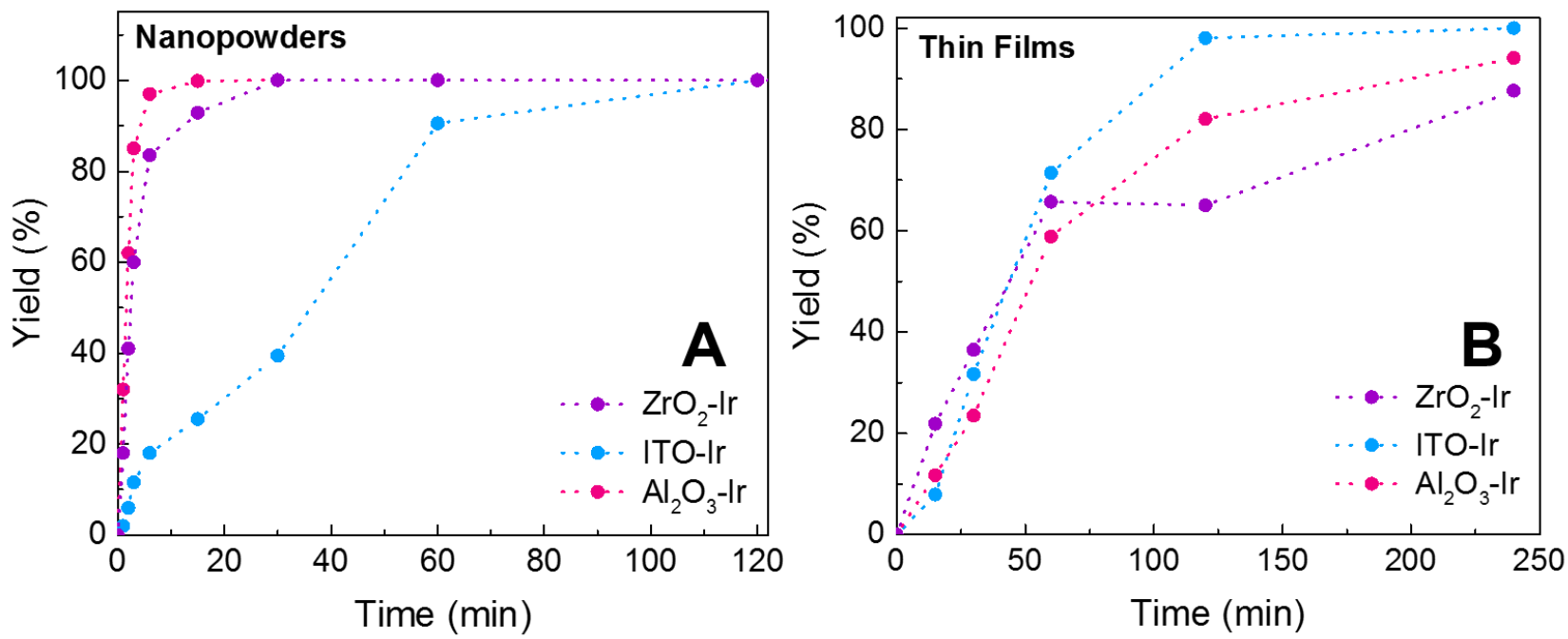

Figure 6. Reaction yield over time during photoredox catalysis using (A) nanopowder and (B) thin film catalysts (ITO-Ir (blue), $\mathrm{Al}_{2} \mathrm{O}_{3}-\mathbf{I r}$ (pink), and $\mathrm{ZrO}_{2}-\mathbf{I r}$ (purple)).

Table 3. Reaction times, TOFs, TONs for the nanopowder and film catalysts.

\begin{tabular}{|c|c|c|c|}
\hline $\begin{array}{c}\text { Nanopowder } \\
\text { Catalysts }\end{array}$ & $\begin{array}{l}\text { Reaction Time } \\
(\min )^{\mathrm{a}}\end{array}$ & TOF $\left(s^{-1}\right)$ & TON (post 3x uses) \\
\hline $\mathrm{Al}_{2} \mathrm{O}_{3}-\mathrm{Ir}$ & 15 & 0.4 & $942^{\mathrm{b}}$ \\
\hline $\mathrm{ZrO}_{2}-\mathrm{Ir}$ & 30 & 0.2 & 663 \\
\hline ITO-Ir & 120 & 0.05 & $777^{\mathrm{b}}$ \\
\hline Film Catalysts & $\begin{array}{l}\text { Reaction Time } \\
(\min )^{\mathrm{a}}\end{array}$ & TOF $\left(s^{-1}\right)$ & TON (post 3x uses) \\
\hline $\mathrm{Al}_{2} \mathrm{O}_{3}-\mathrm{Ir}$ & 240 & 0.025 & $984^{\mathrm{b}}$ \\
\hline $\mathrm{ZrO}_{2}-\mathrm{Ir}$ & 240 & 0.025 & 798 \\
\hline ITO-Ir & 120 & 0.05 & 558 \\
\hline
\end{tabular}

${ }^{\mathrm{a}}$ Time for the reaction to reach completion; ${ }^{\mathrm{b}}$ More turnovers possible.

Thin Film Reactions. Since the nanopowder reactions were highly functional using heterogenized iridium photoredox catalysts, we wanted to test if thin films could also be used for these reactions as they are easier to characterize, easier to remove from the reaction, 
and have possible applications in future (photo)electrochemical setups. Reactions were tracked over time with the thin films placed in the reaction vial, face up, to prevent the stir bar from removing the thin film (see Figure S3). Since there is no catalyst diffusion or transport via stirring with thin films, we expected the reactions to take longer than the nanopowders. Indeed, reactions for both $\mathrm{Al}_{2} \mathrm{O}_{3}$-Ir and $\mathrm{ZrO}_{2}$-Ir films were much slower (Figure 6B), taking four hours to reach completion and perform 385 turnovers, giving them a TOF of $0.025 \mathrm{~s}^{-1}$. Interestingly, ITO-Ir remained the same, taking 2 hours still to complete. Since ITO-Ir nanopowders and films took similar reaction times, this suggests that ITO may not be acting solely as a catalyst platform; perhaps electron transfer events between the catalyst and ITO (such as electron injection) are also occurring during these reactions, which can alter the reaction times.

Comparison to homogeneous Ir. Finally, we were curious how our photoredox catalysts compared to Ir in a homogenous system. When this reaction was followed, we found it was quite similar to the $\mathrm{ZrO}_{2}$-Ir nanopowder system taking 30 minutes to reach completion (Figure S5). Interestingly, the fastest nanoparticle-based heterogenized catalyst, $\mathrm{Al}_{2} \mathrm{O}_{3}-\mathbf{I r}$, operates more efficiently than the homogeneous catalyst. This is noteworthy as $\mathrm{Al}_{2} \mathrm{O}_{3}-\mathbf{I r}$ also has the advantage of being easier to separate from the reaction mixture, making it the more reusable option.

Catalyst Integrity. Since both nanopowder and film catalysts showed excellent photoredox activity, we wanted to check the catalyst integrity after reactions to see if they could be good candidates for reusability measurements. UV-Vis of the thin films showed that Ir was retained on the surface (Figure 7A, S13). ATR-FTIR of the catalysts also indicated that the $\mathrm{C}=\mathrm{C}$ and $\mathrm{C}=\mathrm{N}$ stretches were retained (Figure 7B, S22-23), and XPS showed that iridium remained on the metal oxide supports (Figure 7C, S28-29). These experiments suggest retention of the Ir structure on the surface and that they have the potential to be reusable. 

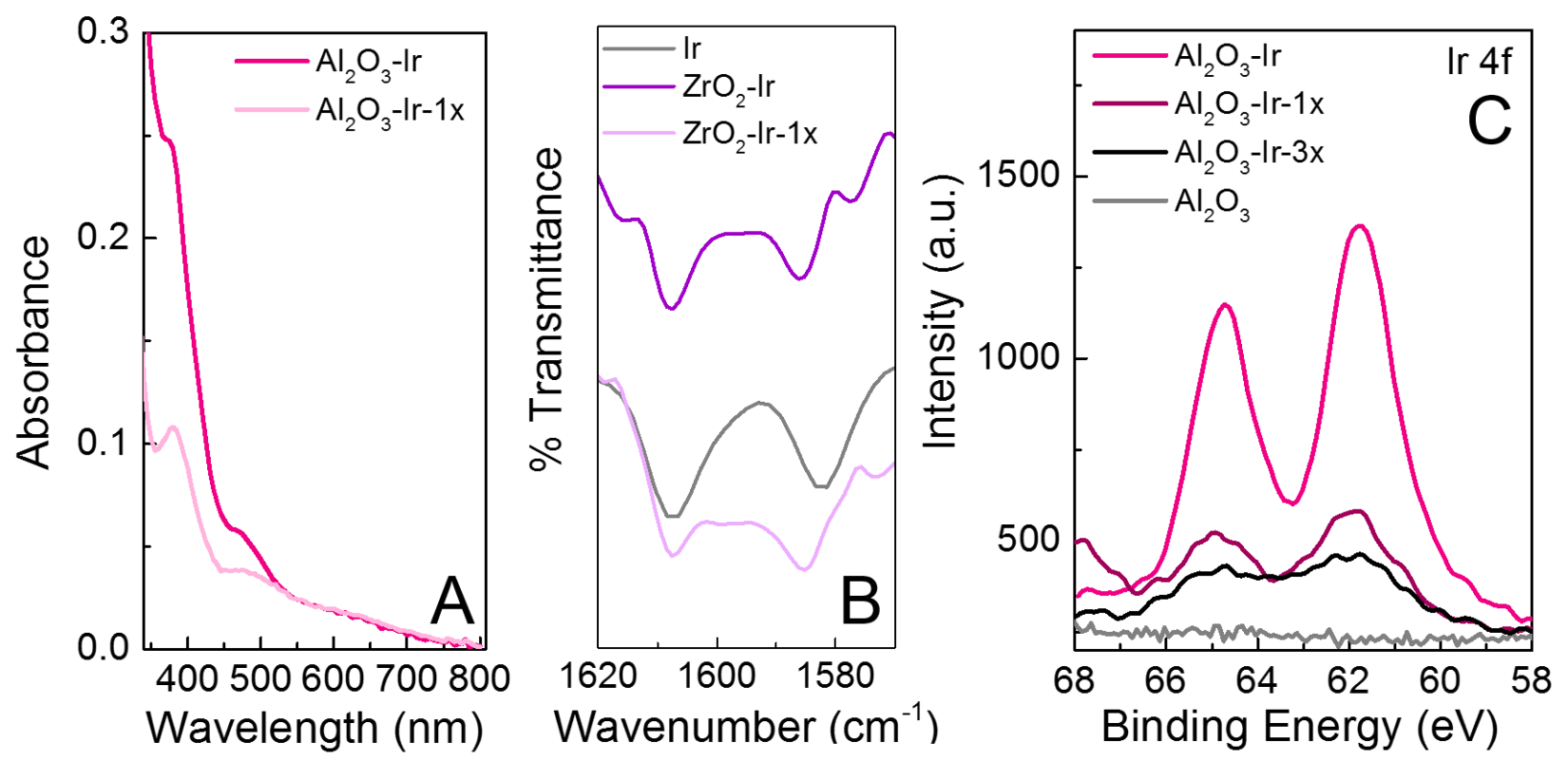

Figure 7. (A) UV-Vis spectra of $\mathrm{Al}_{2} \mathrm{O}_{3}$-Ir before (dark pink) and after (light pink) one photoredox catalytic test. (B) ATR-FTIR spectra of $\mathrm{ZrO}_{2}$-Ir before (dark purple) and after (light purple) one photoredox catalytic test; Ir powder is shown in grey. (C) XPS spectra of $\mathrm{Al}_{2} \mathrm{O}_{3}-\mathbf{I r}$ (dark pink) and $\mathrm{Al}_{2} \mathrm{O}_{3}$ blank (grey). The XPS spectra of $\mathrm{Al}_{2} \mathrm{O}_{3}-\mathbf{I r}$ after one photoredox test is shown in red and after three tests is shown in black.

Catalyst Reusability. Since Ir remained mostly surface-bound after catalysis, reusability experiments were performed to see if the catalysts could be used more than once (Figure 8, Table 3). All catalysts showed good yields over two uses, with yields only dropping slightly to $\sim 90 \%$ for $\mathrm{Al}_{2} \mathrm{O}_{3}-\mathbf{I r}$ and $\mathrm{ZrO}_{2}$-Ir catalysts. ITO-Ir saw a greater drop after two uses to around $\sim 60 \%$ yield (Figure 8 ). After three uses, $\mathrm{ZrO}_{2}$ - Ir nanopowder and film catalysts as well as ITO-Ir nanopowders did not produce APN, suggesting that they had reached maximum turnover; $\mathrm{ZrO}_{2}$-Ir nanopowder performed 663 turnovers, $\mathrm{ZrO}_{2}$-Ir films 798 turnovers, and ITOIr films 588 turnovers prior to losing activity. ITO-Ir nanopowders continued to function after three uses, dropping steadily in yield over the uses to $60 \%$ yield by the end of the third reaction performing 777 turnovers as tested (more possible). The best catalysts for reusability in both films and nanopowders were those of $\mathrm{Al}_{2} \mathrm{O}_{3}$-Ir films, with yields staying above $\sim 80 \%$ yield over three uses, and just at $\sim 80 \%$ for the nanopowders. Clearly, these are the most robust metal oxides for this reaction, and conveniently the fastest catalysts in the nanopowder form. After three uses, $\mathrm{Al}_{2} \mathrm{O}_{3}$-Ir films performed 984 turnovers and nanopowders 942 turnovers, with more turnovers possible as they may be able to be reused further. Table 3 summarizes the TONs from the reusability tests. 

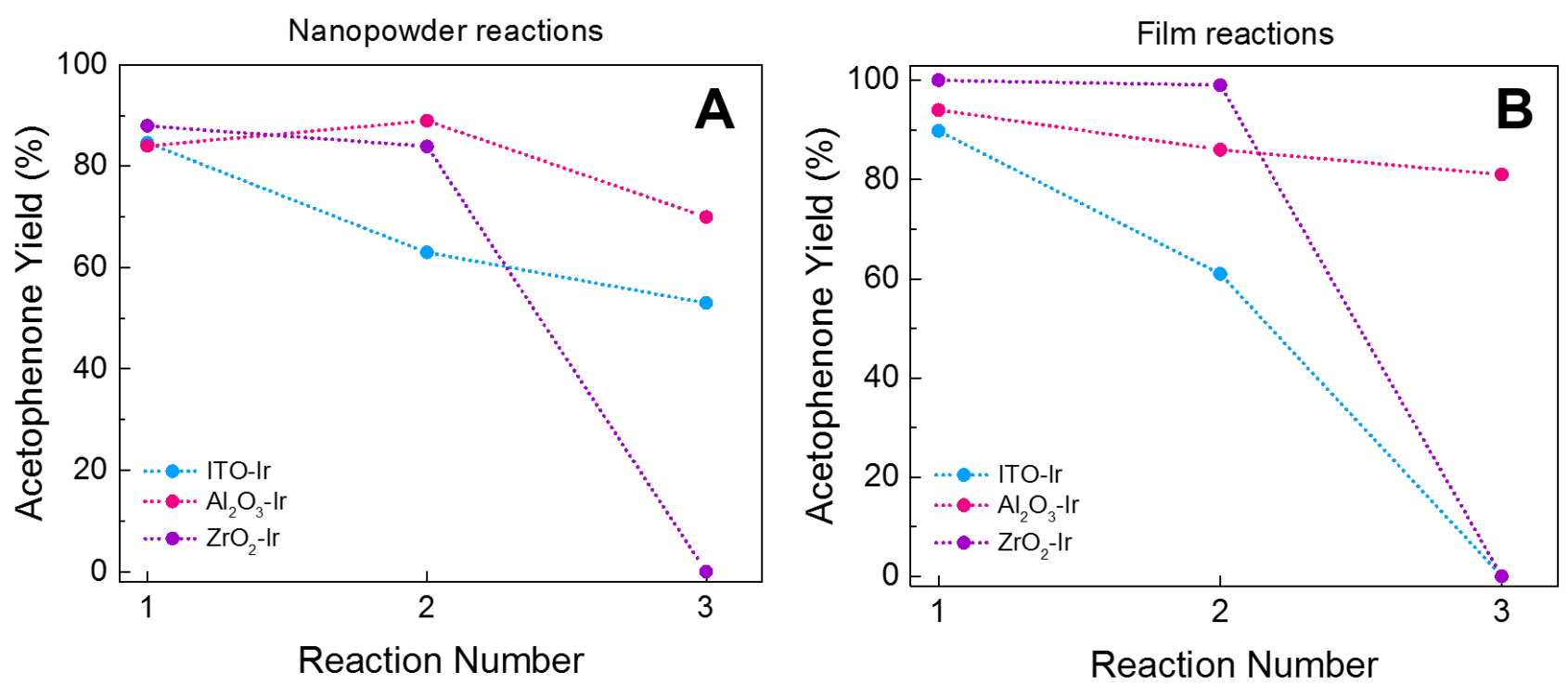

Figure 8. Reaction yields for three sequential photoredox tests for (A) nanopowder catalysts and (B) thin film catalysts; ITO-Ir (blue), $\mathrm{Al}_{2} \mathrm{O}_{3}-\mathbf{I r}$ (pink), $\mathrm{ZrO}_{2}-\mathbf{I r}$ (purple).

Furthermore, $\mathrm{Al}_{2} \mathrm{O}_{3}$ and ITO films were the most robust supports, as no metal oxide film loss was observed after the reactions, unlike $\mathrm{ZrO}_{2}$ films, which peeled away under the reaction conditions, likely limiting the reusability. Nanopowder reactions, although faster, do lose some of the initial $\mathrm{MO}_{\mathrm{x}}$-Ir starting mass after each use due to losses during centrifugation and rinsing steps, even up to $50 \%$ of the initial catalyst mass by the start of reaction three (Figure S6). Clearly, as the $\mathrm{Al}_{2} \mathrm{O}_{3}$ and ITO films are retained after each use, these are the most robust and easily reusable platforms. Regardless, as all catalysts were reusable at least twice, this highlights that heterogenized catalysts have the potential to be used as an environmentally friendly alternative way to do photoredox catalysis when fully optimized.

Catalyst Integrity after Reusability. To understand why some of the catalysts were not as reusable, they were characterized again after three uses. Characterization of the film samples by UV-Vis showed catalyst loss or degradation after each use with Ir signature bands decreasing after each use (Figure S14), and similarly when ATR-FTIR was used (Figure S2425). XPS still showed iridium content on most of the metal oxides, demonstrating that the catalyst had not fully desorbed (Figure S30-31). Based on these results, some of the iridium complex has been removed from the metal oxide surface after three uses, which could be a reason for the loss in activity with some catalysts.

Reaction Mixtures. To further understand what was happening during catalysis, we examined the UV-Vis spectra of the reaction mixtures post catalysis during the reusability 
tests. The UV-Vis spectra of the reaction mixtures after the first two reactions showed a species present in the UV-Vis spectra (Figure S15-16). The species observed differed depending on what catalyst was used, and could be either a desorbed, degraded, or reduced Ir species. Note that the spectra did not match that of Ir for nearly all of the catalysts with the exception being from the ITO-Ir nanopowder reactions where the UV-Vis spectra from the first reaction appeared to mimic Ir, suggesting some $\mathbf{I r}$ desorption in this specific case.

To understand the origin of these species, we tested to see if they were formed before or during catalysis. First, controls were performed to examine if the species was formed prior to catalysis by soaking the $\mathrm{MO}_{\mathrm{x}}-\mathbf{I r}$ films in the dark in the presence of acetonitrile solutions of BrAPN, TEOA, a mixture of both (Figure S18). Recall, that solvent and light alone, does not desorb Ir (Figure S17). We found that a species desorbs when films are exposed to both BrAPN and TEOA prior to catalytic measurements (prior to LED exposure), which has absorption bands around $400 \mathrm{~nm}$ and $500 \mathrm{~nm}$ (Figure S18F); this spectrum is similar to that of Ir, but has shifted slightly, which could suggest some changes in the ligand environment of the iridium complex due to exposure to both BrAPN and TEOA. This suggests that prior to illumination, some desorbed/altered iridium species is already present in the reaction mixture. However, these spectra do not match that of the reaction mixtures post catalysis, suggesting that i) the species that desorbs prior to catalysis may change some during photoredox catalysis or ii) that another degraded/changed species desorbs from the metal oxide surface during catalysis. We note that soaking the catalyst in an APN acetonitrile mixture does not match these spectra either, suggesting that APN does not aid in forming the species. For now, it is clear that an iridium species is appearing in the reaction mixtures, but it is different from Ir. Importantly, recall that when the catalyst is removed from the reaction mixture during catalysis (Figure 4), the reaction mixture alone does not show catalytic activity. Thus, we conclude that these desorbed/degraded species are likely innocent during catalysis as they are possibly i) an inactive complex slightly different than Ir or ii) too low in concentration to contribute to catalysis. Nonetheless, loss of the surface species or degradation is likely a reason for some loss in catalytic activity for some of the samples, and will be optimized and investigated further in future work.

\section{Conclusions}

In this study, we have performed a systematic study to analyze the effect of the catalyst support in heterogenized iridium photoredox catalysts. Three metal oxide supports 
were examined in both nanopowder and thin film form, and all catalysts were found to be functional for reductive dehalogenation reactions to form acetophenone. Significantly, the fastest catalyst, nanopowder $\mathrm{Al}_{2} \mathrm{O}_{3}$-Ir, was able to reach reaction completion in nearly 15 minutes, which is slightly faster than the homogenous system. Thin film-based catalysts also gave high yields, but operated slower (2-4 hours) than their nanopowder counterparts due to no catalyst diffusion or transport via stirring. However, thin films provide more applicable architectures in future (photo)electrochemical photoredox catalytic studies and additionally, were more easily reused. Post catalysis, all catalysts showed good surface stability and were able to be reused at least 2-3 times. The most reusable catalysts were $\mathrm{Al}_{2} \mathrm{O}_{3}-\mathbf{I r}$ (both film and nanopowder) showing a limited drop in yield after recycling, which approached 1000 turnovers after three uses, further highlighting that these catalysts can be used to do efficient photoredox catalysis in an environmentally friendly fashion. Thus, of the three surfaces, $\mathrm{Al}_{2} \mathrm{O}_{3}$ is the optimal metal oxide, and thin film supports are preferred over the nanopowders as they are the most easily reused and greener options; in future work, catalysts will be further explored with these architectures. Since some surface instability was observed during the reactions, catalyst stability on the metal oxide will be improved in future investigations by using stronger surface anchors or through the addition of surface protecting layers. Finally, we hope to have shown here that heterogenized catalysts have a great potential to be used in the photoredox community, bringing together both the tunability of homogeneous systems and reusability of heterogeneous systems in one complete, environmentally friendly catalyst.

Associated Content: Further experimental details on catalyst preparation and characterizations, reaction conditions, and NMR quantifications can be found in the Supporting information (SI). Additional UV-Vis, ATR-FTIR, photoluminescence, XPS, and NMR spectra and TCSPC results can also be found in the SI.

Notes: The authors declare no competing financial interest.

Acknowledgements: We thank the Foundation Olle Engkvist Byggmästare (SOEB, grant 200-0565) and Knut and Alice Wallenberg Foundation (grant 2019.0071) for funding this research. We also thank Dr. Anna Arkhypchuk for aiding in experimental setups and Nidhi Kaul for helping with TCSPC measurements. We also thank Dr. Anna M. Beiler, Dr. Anna Arkhypchuk, and Dr. Haining Tian for providing feedback on the manuscript.

\section{References}


1. Administration, U. S. E. I. Annual Energy Outlook; DC, 2017.

2. IEA World Energy Outlook 2020. https://www.iea.org/reports/world-energy-outlook-2020

3. Gibson, E. A., Dye-Sensitized Photocathodes for H2 Evolution. Chem Soc Rev 2017, 46 (20), 6194-6209.

4. Swierk, J. R.; Mallouk, T. E., Design and Development of Photoanodes for Water-Splitting Dye-Sensitized Photoelectrochemical Cells. Chem Soc Rev 2013, 42 (6), 2357-2387.

5. Ashford, D. L.; Gish, M. K.; Vannucci, A. K.; Brennaman, M. K.; Templeton, J. L.;

Papanikolas, J. M.; Meyer, T. J., Molecular Chromophore-Catalyst Assemblies for Solar Fuel Applications. Chem. Rev. 2015, 115 (23), 13006-13049.

6. Yu, Z.; Li, F.; Sun, L., Recent Advances in Dye-Sensitized Photoelectrochemical Cells for Solar Hydrogen Production Based on Molecular Components. Energy \& Environmental Science 2015, 8 (3), 760-775.

7. Brennaman, M. K.; Dillon, R. J.; Alibabaei, L.; Gish, M. K.; Dares, C. J.; Ashford, D. L.; House, R. L.; Meyer, G. J.; Papanikolas, J. M.; Meyer, T. J., Finding the Way to Solar Fuels with Dye-Sensitized Photoelectrosynthesis Cells. J. Am. Chem. Soc. 2016, 1308513102.

8. Nazeeruddin, M. K.; Baranoff, E.; Grätzel, M., Dye-Sensitized Solar Cells: A Brief Overview. Solar Energy 2011, 85 (6), 1172-1178.

9. Zhang, S.; Ye, H.; Hua, J.; Tian, H., Recent Advances in Dye-Sensitized

Photoelectrochemical Cells for Water Splitting. EnergyChem 2019, 1 (3).

10. Wang, D.; Farnum, B. H.; Dares, C. J.; Meyer, T. J., Chemical Approaches to Artificial Photosynthesis: A Molecular, Dye-Sensitized Photoanode for O2 Production Prepared by Layer-by-Layer Self-Assembly. J Chem Phys 2020, 152 (24), 244706.

11. Antila, L. J.; Ghamgosar, P.; Maji, S.; Tian, H.; Ott, S.; Hammarström, L., Dynamics and Photochemical H2 Evolution of Dye-Nio Photocathodes with a Biomimetic FefeCatalyst. ACS Energy Letters 2016, 1 (6), 1106-1111.

12. D'Amario, L.; Antila, L. J.; Pettersson Rimgard, B.; Boschloo, G.; Hammarstrom, L., Kinetic Evidence of Two Pathways for Charge Recombination in Nio-Based Dye-Sensitized Solar Cells. J Phys Chem Lett 2015, 6 (5), 779-783.

13. D'Amario, L.; Föhlinger, J.; Boschloo, G.; Hammarström, L., Unveiling Hole Trapping and Surface Dynamics of Nio Nanoparticles. Chemical Science 2018, 9 (1), 223-230.

14. D'Amario, L.; Jiang, R.; Cappel, U. B.; Gibson, E. A.; Boschloo, G.; Rensmo, H.; Sun, L.; Hammarstrom, L.; Tian, H., Chemical and Physical Reduction of High Valence Ni States in Mesoporous Nio Film for Solar Cell Application. ACS Appl Mater Interfaces 2017, 9 (39), 33470-33477.

15. Daeneke, T.; Yu, Z.; Lee, G. P.; Fu, D. C.; Duffy, N. W.; Makuta, S.; Tachibana, Y.; Spiccia, L.; Mishra, A.; Baeuerle, P.; Bach, U., Dominating Energy Losses in Nio P-Type Dye-Sensitized Solar Cells. Advanced Energy Materials 2015, 5 (4).

16. Mori, S.; Fukuda, S.; Sumikura, S.; Takeda, Y.; Tamaki, Y.; Suzuki, E.; Abe, T., Charge-Transfer Processes in Dye-Sensitized Nio Solar Cells. The Journal of Physical Chemistry C 2008, 112 (41), 16134-16139.

17. Shan, B.; Nayak, A.; Brennaman, M. K.; Liu, M.; Marquard, S. L.; Eberhart, M. S.; Meyer, T. J., Controlling Vertical and Lateral Electron Migration Using a Bifunctional Chromophore Assembly in Dye-Sensitized Photoelectrosynthesis Cells. J Am Chem Soc 2018, 140 (20), 6493-6500.

18. Shan, B.; Sherman, B. D.; Klug, C. M.; Nayak, A.; Marquard, S. L.; Liu, Q.; Bullock, R. M.; Meyer, T. J., Modulating Hole Transport in Multilayered Photocathodes with Derivatized P-Type Nickel Oxide and Molecular Assemblies for Solar-Driven Water Splitting. J Phys Chem Lett 2017, 8 (18), 4374-4379. 
19. Bloh, J. Z.; Marschall, R., Heterogeneous Photoredox Catalysis: Reactions, Materials, and Reaction Engineering. European Journal of Organic Chemistry 2017, 2017 (15), 2085-2094. 20. McAtee, R. C.; McClain, E. J.; Stephenson, C. R. J., Illuminating Photoredox Catalysis. Trends in Chemistry 2019, 1 (1), 111-125.

21. Reckenthäler, M.; Griesbeck, A. G., Photoredox Catalysis for Organic Syntheses. Advanced Synthesis \& Catalysis 2013, 355 (14-15), 2727-2744.

22. Romero, N. A.; Nicewicz, D. A., Organic Photoredox Catalysis. Chem Rev 2016, 116 (17), 10075-10166.

23. Shaw, M. H.; Twilton, J.; MacMillan, D. W., Photoredox Catalysis in Organic Chemistry. J Org Chem 2016, 81 (16), 6898-6926.

24. Stephenson, C. Y., T.; MacMillan, D.W.C., Visible Light Photocatalysis in Organic Chemistry. Wiley-VCH Verlag GmbH \& Co. KGaA 2018.

25. Hockin, B. M.; Li, C.; Robertson, N.; Zysman-Colman, E., Photoredox Catalysts Based on Earth-Abundant Metal Complexes. Catalysis Science \& Technology 2019, 9 (4), 889-915. 26. Lentz, C.; Marcélis, L.; Troian-Gautier, L.; Robeyns, K.; Cauët, E.; Elias, B., ExcitedState Behavior and Photoinduced Electron Transfer of Ph-Sensitive $\operatorname{Ir}(\mathrm{Iii})$ Complexes with Cyclometallation ( $\mathrm{C} / \mathrm{N}-)$ Ratios between 0/6 and 3/3. Journal of Photochemistry and Photobiology A: Chemistry 2021, 405.

27. Materna, K. L.; Jiang, J.; Regan, K. P.; Schmuttenmaer, C. A.; Crabtree, R. H.; Brudvig, G. W., Optimization of Photoanodes for Photocatalytic Water Oxidation by Combining a Heterogenized Iridium Water-Oxidation Catalyst with a High-Potential Porphyrin Photosensitizer. ChemSusChem 2017, 10 (22), 4526-4534.

28. Materna, K. L.; Rudshteyn, B.; Brennan, B. J.; Kane, M. H.; Bloomfield, A. J.; Huang, D. L.; Shopov, D. Y.; Batista, V. S.; Crabtree, R. H.; Brudvig, G. W., Heterogenized Iridium Water-Oxidation Catalyst from a Silatrane Precursor. ACS Catal. 2016, 6 (8), 53715377.

29. Tian, H., Molecular Catalyst Immobilized Photocathodes for Water/Proton and Carbon Dioxide Reduction. ChemSusChem 2015, 8 (22), 3746-3759.

30. Barbante, G. J.; Ashton, T. D.; Doeven, E. H.; Pfeffer, F. M.; Wilson, D. J. D.; Henderson, L. C.; Francis, P. S., Photoredox Catalysis of Intramolecular Cyclizations with a Reusable Silica-Bound Ruthenium Complex. ChemCatChem 2015, 7 (11), 1655-1658. 31. Tambosco, B.; Segura, K.; Seyrig, C.; Cabrera, D.; Port, M.; Ferroud, C.; Amara, Z., Outer-Sphere Effects in Visible-Light Photochemical Oxidations with Immobilized and Recyclable Ruthenium Bipyridyl Salts. ACS Catalysis 2018, 8 (5), 4383-4389.

32. Teixeira, R. I.; de Lucas, N. C.; Garden, S. J.; Lanterna, A. E.; Scaiano, J. C., Glass Wool Supported Ruthenium Complexes: Versatile, Recyclable Heterogeneous Photoredox Catalysts. Catalysis Science \& Technology 2020, 10 (5), 1273-1280.

33. Liang, Y.; Bergbreiter, D. E., Visible Light Mediated Photoredox Reactions Catalyzed by Recyclable Pib-Bound Ruthenium Photoredox Catalysts. Catalysis Science \& Technology 2016, 6 (1), 215-221.

34. Soria-Castro, S. M.; Lebeau, B.; Cormier, M.; Neunlist, S.; Daou, T. J.; Goddard, J.-P., Organic/Inorganic Heterogeneous Silica-Based Photoredox Catalyst for Aza-Henry

Reactions. European Journal of Organic Chemistry 2020, 2020 (10), 1572-1578.

35. Carrillo, A. I.; Elhage, A.; Marin, M. L.; Lanterna, A. E., Perylene-Grafted Silicas:

Mechanistic Study and Applications in Heterogeneous Photoredox Catalysis. Chemistry 2019, 25 (65), 14928-14934.

36. Chu, Y.; Corrigan, N.; Wu, C.; Boyer, C.; Xu, J., A Process for Well-Defined Polymer Synthesis through Textile Dyeing Inspired Catalyst Immobilization. ACS Sustainable Chemistry \& Engineering 2018, 6 (11), 15245-15253. 
37. Zhi, P.; Xi, Z.-W.; Wang, D.-Y.; Wang, W.; Liang, X.-Z.; Tao, F.-F.; Shen, R.-P.; Shen, Y.-M., Vilsmeier-Haack Reagent Mediated Synthetic Transformations with an Immobilized Iridium Complex Photoredox Catalyst. New Journal of Chemistry 2019, 43 (2), 709-717.

38. Yoo, W.-J.; Kobayashi, S., Efficient Visible Light-Mediated Cross-Dehydrogenative Coupling Reactions of Tertiary Amines Catalyzed by a Polymer-Immobilized Iridium-Based Photocatalyst. Green Chem. 2014, 16 (5), 2438-2442.

39. Santiago-Portillo, A.; Baldoví, H. G.; Carbonell, E.; Navalón, S.; Álvaro, M.; García, H.; Ferrer, B., Ruthenium(Ii) Tris(2,2'-Bipyridyl) Complex Incorporated in Uio-67 as Photoredox Catalyst. The Journal of Physical Chemistry C 2018, 122 (51), 29190-29199. 40. Wang, Z. J.; Ghasimi, S.; Landfester, K.; Zhang, K. A. I., A Conjugated Porous PolyBenzobisthiadiazole Network for a Visible Light-Driven Photoredox Reaction. J. Mater. Chem. A 2014, 2 (44), 18720-18724.

41. Santiago-Portillo, A.; Remiro-Buenamanana, S.; Navalon, S.; Garcia, H., Subphthalocyanine Encapsulated within Mil-101(Cr)-Nh2 as a Solar Light Photoredox Catalyst for Dehalogenation of Alpha-Haloacetophenones. Dalton Trans 2019, 48 (48), 17735-17740.

42. Martinez-Haya, R.; Miranda, M. A.; Marin, M. L., Metal-Free Photocatalytic Reductive Dehalogenation Using Visible-Light: A Time-Resolved Mechanistic Study. European Journal of Organic Chemistry 2017, 2017 (15), 2164-2169.

43. Prier, C. K.; Rankic, D. A.; MacMillan, D. W., Visible Light Photoredox Catalysis with Transition Metal Complexes: Applications in Organic Synthesis. Chem Rev 2013, 113 (7), 5322-5363.

44. Monos, T. M. S., C., Iridium(Iii) in Optoelectronic and Photonics Applications. In Photoredox Catalysis of Iridium(III)-Based Photosensitizers, Ch11 [Online] Zysman-Colman, E., Ed. John Wiley \& Sons Ltd.: 2017.

45. Materna, K. L.; Crabtree, R. H.; Brudvig, G. W., Anchoring Groups for Photocatalytic Water Oxidation on Metal Oxide Surfaces. Chem Soc Rev 2017, 46 (20), 6099-6110. 46. Waern, J. B.; Desmarets, C.; Chamoreau, L. M.; Amouri, H.; Barbieri, A.; Sabatini, C.; Ventura, B.; Barigelletti, F., Luminescent Cyclometalated Rh(Iii), $\operatorname{Ir}($ Iii), and (Dip)2ru(Ii) Complexes with Carboxylated Bipyridyl Ligands: Synthesis, X-Ray Molecular Structure, and Photophysical Properties. Inorg Chem 2008, 47 (8), 3340-3348.

47. Rehm, D.; Weller, A., Kinetics and Mechanics of Electron Transfer During Fluorescence Quenching in Acetonitrile. Ber. Bunsenges 1969, 73, 834-830.

48. Palomares, E.; Clifford, J. N.; Haque, S. A.; Lutz, T.; Durrant, J. R., Control of Charge Recombination Dynamics in Dye Sensitized Solar Cells by the Use of Conformally Deposited Metal Oxide Blocking Layers. J Am Chem Soc 2003, 125 (2), 475-482.

49. Alibabaei, L.; Dillon, R. J.; Reilly, C. E.; Brennaman, M. K.; Wee, K. R.; Marquard, S. L.; Papanikolas, J. M.; Meyer, T. J., Chromophore-Catalyst Assembly for Water Oxidation Prepared by Atomic Layer Deposition. ACS Appl Mater Interfaces 2017, 9 (44), 3901839026.

50. Materna, K. L.; Lalaoui, N.; Laureanti, J. A.; Walsh, A. P.; Rimgard, B. P.; Lomoth, R.; Thapper, A.; Ott, S.; Shaw, W. J.; Tian, H.; Hammarstrom, L., Using Surface Amide Couplings to Assemble Photocathodes for Solar Fuel Production Applications. ACS Appl Mater Interfaces 2020, 12 (4), 4501-4509.

51. Trammell, S. A.; Meyer, T. J., Diffusional Mediation of Surface Electron Transfer on Tio2. The Journal of Physical Chemistry B 1999, 103 (1), 104-107.

52. Weller, A., Photoinduced Electron Transfer in Solution: Exciplex and Radical Ion Pair Formation Free Enthalpies and Their Solvent Dependence. Zeitschrift für Physikalische Chemie 1982, 133 (1), 93-98. 
53. Pellegrin, Y.; Odobel, F., Sacrificial Electron Donor Reagents for Solar Fuel Production. Comptes Rendus Chimie 2017, 20 (3), 283-295.

54. Kjaer, K. S.; Kaul, N.; Prakash, O.; Chabera, P.; Rosemann, N. W.; Honarfar, A.; Gordivska, O.; Fredin, L. A.; Bergquist, K. E.; Haggstrom, L.; Ericsson, T.; Lindh, L.; Yartsev, A.; Styring, S.; Huang, P.; Uhlig, J.; Bendix, J.; Strand, D.; Sundstrom, V.; Persson, P.; Lomoth, R.; Warnmark, K., Luminescence and Reactivity of a Charge-Transfer Excited Iron Complex with Nanosecond Lifetime. Science 2019, 363 (6424), 249-253. 55. El-Zohry, A.; Orthaber, A.; Zietz, B., Isomerization and Aggregation of the Solar Cell Dye D149. J Phys Chem C Nanomater Interfaces 2012, 116 (50), 26144-26153.

56. Afanas'ev, V. V.; Stesmans, A., Stable Trapping of Electrons and Holes in Deposited Insulating Oxides: Al2o3, Zro2, and Hfo2. Journal of Applied Physics 2004, 95 (5), 25182526.

57. Novikov, Y. N.; Gritsenko, V. A.; Nasyrov, K. A., Charge Transport Mechanism in Amorphous Alumina. Applied Physics Letters 2009, 94 (22). 